\title{
Evaluation of the intraepithelial lymphocyte count in the jejunum in childhood enteropathies
}

\author{
J. MAVROMICHALIS, M. J. BRUETON, A. S. McNEISH, AND C. M. ANDERSON \\ From the Institute of Child Health, University of Birmingham, Birmingham
}

SUMMARY Intraepithelial lymphocyte counts were evaluated in 131 jejunal mucosal biopsies taken from children with a small intestinal enteropathy arising from a variety of causes including coeliac disease, (untreated, after gluten withdrawal, and during subsequent challenge), giardiasis, cow's milk protein intolerance, and 'intractable diarrhoea'. The counts were compared with those from the biopsies of children referred for investigation but in whom no gastrointestinal disease was demonstrated and from healthy siblings of children with coeliac disease, investigated during a family study. Children with coeliac disease showed a raised count which fell after gluten withdrawal as has been demonstrated by others in adults. Lymphocytic infiltration of the epithelium increased rapidly during gluten challenge in such children, while no change was seen in those children proven ultimately not to have coeliac disease by the usually recognized criteria. In other enteropathies the range of counts was wide, overlapping with both normal and coeliac groups and indicating the nonspecificity of lymphocytic infiltration of the gut epithelium. The findings are discussed in relation to their significance and to further avenues of investigation to determine their possible diagnostic value in confirming the diagnosis of coeliac disease during gluten challenge.

The presence of increased numbers of lymphocytes between the epithelial cells of the jejunal mucosa of adults with untreated coeliac disease (CD) was described by Hourihane in 1966. Ferguson and Murray (1971) quantitated this observation and showed that these intraepithelial lymphocytes fell, although rarely to normal levels, after a period of gluten withdrawal. This was confirmed in adult $\mathrm{CD}$ by Holmes et al. (1974), and in dermatitis herpetiformis by Fry et al. (1972), and Kumar et al. (1973). The purpose of the present communication is to record counts made of intraepithelial lymphocytes in children without gastrointestinal disease ('normals') and in those with small intestinal disease from a variety of causes. An evaluation of serial changes in the count has been made in children with gluten sensitive enteropathy (CD) before treatment, during remission, and after a gluten challenge.

\section{Methods}

One-hundred-and-thirty-one jejunal mucosal biopsies were reviewed; all had been taken from the region of the ligament of Treitz and were from

Received for publication 7 April 1976 children aged between 9 months and 6.5 years. They will be considered under five groupings.

Group I Twenty-nine were from children whose biopsies were considered normal by light microscopy ('normals'); of these 17 had been referred for investigation of possible malabsorption but comprehensive investigation revealed no gastrointestinal dysfunction; 12 had been previously diagnosed as coeliac disease on inadequate criteria and were finally considered not to have this condition because their jejunal histology remained normal after periods of 11-13 weeks of dietary gluten $(20 \mathrm{~g} /$ day $)$ and subsequent follow-up for one to two years on normal diets.

Group II Thirty-four were from children who were normal siblings of coeliacs. They were investigated as part of a family study.

Group III Twelve were from untreated coeliacs.

Group IV Eleven were from children with CD who had been on a gluten free diet for from 1.5 to 10 years, and who were then challenged with gluten $(20 \mathrm{~g} /$ day $)$ for from four to nine weeks before a further jejunal biopsy.

Group $V$ Twenty-two were from children with enteropathies associated with giardiasis (10 patients), cow's milk protein intolerance (four patients), and 
'intractable diarrhoea' (eight patients). All in this latter group had been referred because of diarrhoea of unknown aetiology which had been present for at least several weeks, with an onset under the age of 6 months in all but one case.

Epithelial cells and intraepithelial lymphocytes were counted in sections stained with haematoxylin and eosin whose plane passed vertically though the epithelium and the underlying basement membrane. Counts were made near the tips of the villi, while, in those biopsies which showed total villous atrophy, the surface cells were counted. In each specimen at least 500 cell nuclei (epithelial and lymphocyte) were enumerated, all the mononuclear non-epithelial cells were referred to as lymphocytes, and the results were expressed as the number of intraepithelial lymphocytes per 100 epithelial cells (Ferguson and Murray, 1971). The biopsies were graded according to the classification described in the Table.

\section{Results}

Details of the patients studied, the histological grading of their jejunal biopsies, and the mean number of intraepithelial lymphocytes per 100 epithelial cells are displayed in the Table. The distribution of the individual counts is shown in Fig. 1. There was no correlation with the age or sex of the patients.

The intraepithelial lymphocyte counts in groups I and II, the 'normals', were similar and significantly less $(P<0.001)$ than group III, the untreated coeliac group. Although the mean count of group IV, the treated coeliacs, was lower than group III, it remained higher than the mean of the 'normals'. After a gluten challenge there was a significant rise in the count $(\mathrm{P}<0.001)$ in the coeliac patients (Fig. 2), but not in the 'normal' group (Fig. 3). In the latter there was no change in the histological grading of the jejunal mucosa after gluten challenge.

The wide range of counts seen in the patients with other enteropathies (group V) was wide, overlapping both 'normals' and coeliac groups. In this group many of the biopsies with morphologically abnormal villi had normal intraepithelial lymphocyte counts, in contrast with the untreated coeliac patients in group III with biopsies graded histologically as 2 or 3, which all showed increased lymphocytic infiltration of the epithelium.

\section{Discussion}

We have confirmed in children that, as in adults with untreated $C D$, lymphocytic infiltration of the jejunal epithelium is increased, the mean count falling after the institution of a gluten free diet, but remaining higher than the mean of a group without intestinal disease. It may be that this latter observation reflects continued ingestion of small amounts of gluten in the diet (Dissanayake et al., 1974). The consistent rise in intraepithelial lymphocytes after a gluten challenge in the treated coeliac group, in comparison with the 'normals', enabled a clear distinction between the groups to be made. This finding might serve as an index of gluten sensitivity during a gluten challenge. Normally, significant gross morphological change during such a challenge may not be demonstrated for months or even for one to two years. The period of gluten challenge could be materially shortened if a raised intraepithelial lymphocyte count could be consistently shown to antedate significant morphological changes. Our observations on a relatively small number of patients suggest that further study of this point would be useful.

The finding of a raised count in some patients

Table Patient groups, mean ages, jejunal biopsy grading, and intraepithelial lymphocyte counts

\begin{tabular}{|c|c|c|c|c|c|c|c|c|}
\hline \multirow[t]{2}{*}{ Patient groups } & \multirow[t]{2}{*}{$\begin{array}{l}\text { No. of } \\
\text { patients }\end{array}$} & \multirow[t]{2}{*}{$\begin{array}{l}\text { Mean age } \\
(y r)\end{array}$} & \multicolumn{4}{|c|}{$\begin{array}{l}\text { Histological grading* of jejunal } \\
\text { biopsy (no. in each group) }\end{array}$} & \multicolumn{2}{|c|}{$\begin{array}{l}\text { Intraepithelial lymphocytes } \\
\text { per } 100 \text { epithelial cells }\end{array}$} \\
\hline & & & 1 & 2 & 3 & 4 & Mean $\pm 1 S D$ & Range \\
\hline $\begin{array}{l}\text { I. 'Normal'-no gastrointestinal disease } \\
\text { 'Normal'-after gluten challenge } \\
\text { II. Normal' siblings of coeliacs } \\
\text { III. Untreated coeliacs } \\
\text { IV. Coeliacs }\end{array}$ & $\left.\begin{array}{r}17 \\
12\end{array}\right\} \begin{array}{r}29 \\
34 \\
12\end{array}$ & $\begin{array}{l}4 \frac{1}{2} \\
5 \frac{1}{2} \\
6 \frac{1}{2} \\
2 \frac{1}{1}\end{array}$ & $\begin{array}{l}17 \\
12 \\
34 \\
-\end{array}$ & $\frac{-}{-}$ & $\frac{-}{2}$ & $\frac{-}{\frac{-}{9}}$ & $\begin{array}{l}15 \pm 4 \\
16 \pm 4 \\
17 \pm 8 \\
68 \pm 19\end{array}$ & $\begin{array}{c}8-27 \\
11-26 \\
7-40 \\
37-108\end{array}$ \\
\hline $\begin{array}{l}\text { on a gluten free diet } \\
\text { after gluten challenge } \\
\text { V. Giardiasis } \\
\text { Cow's milk protein intolerance } \\
\text { 'Intractable diarrhoea' }\end{array}$ & $\left.\begin{array}{r}10 \\
4 \\
8\end{array}\right\} 22$ & $\begin{array}{l}3 \\
8 \\
1\end{array}$ & $\begin{array}{l}11 \\
6 \\
1 \\
4\end{array}$ & $\begin{array}{l}- \\
4 \\
1 \\
2\end{array}$ & $\frac{-}{3}$ & $\overline{-}$ & $\begin{array}{l}25 \pm 4 \\
49 \pm 7 \\
29 \pm 18 \\
19 \pm 13 \\
22 \pm 15\end{array}$ & $\begin{array}{r}16-32 \\
40-67 \\
7-55 \\
10-38 \\
9-50\end{array}$ \\
\hline
\end{tabular}

* Grade 1 : normal finger or leaf villi: epithelial cells normal.

Grade 2: villi broadened: epithelial cells irregular; increase of cells in lamina propria.

Grade 3: fused, stunted villi: moderate infiltrate in lamina propria.

Grade 4: absence of villi: crypt hyperplasia. 

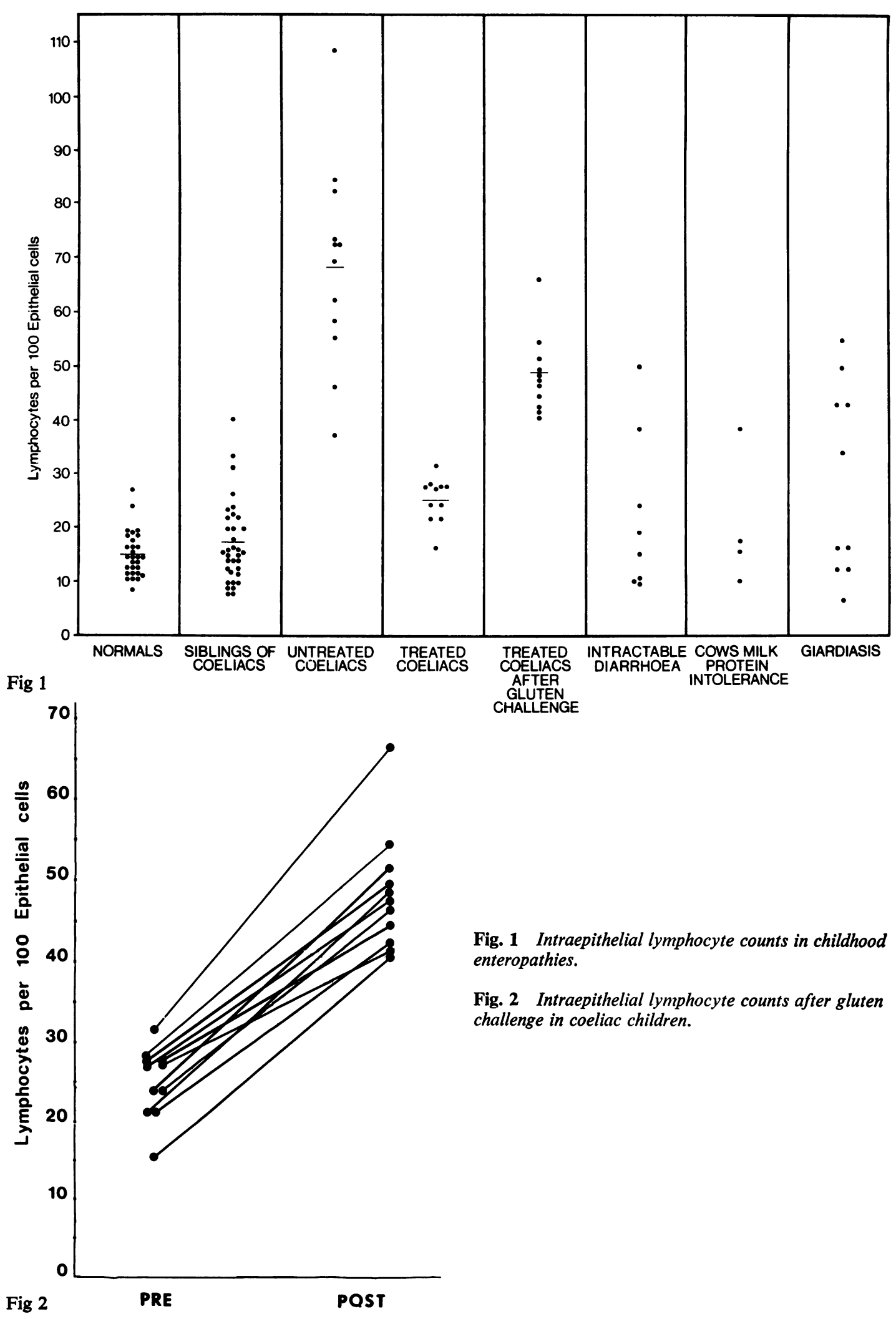

Fig. 1 Intraepithelial lymphocyte counts in childhood enteropathies.

Fig. 2 Intraepithelial lymphocyte counts after gluten challenge in coeliac children. 


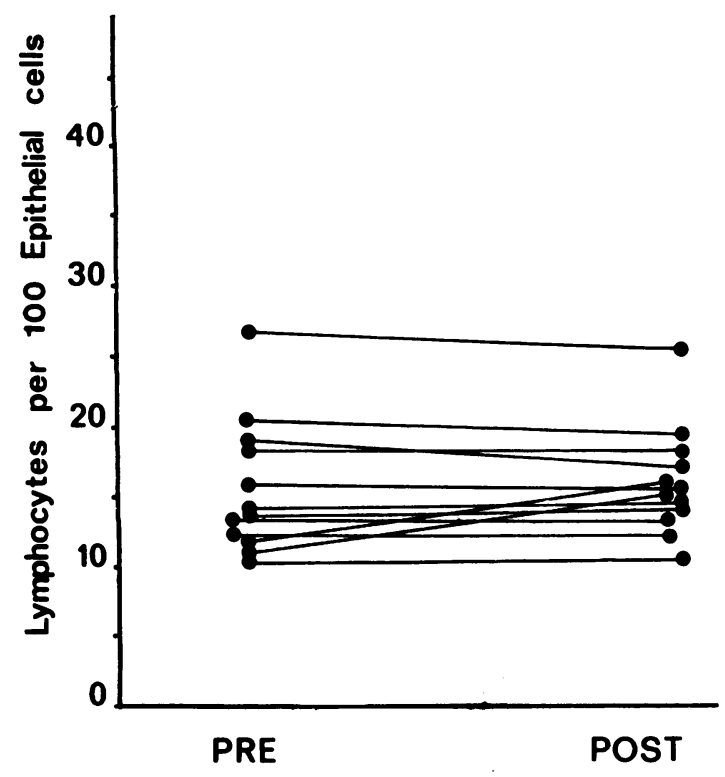

Fig. 3 Intraepithelial lymphocyte counts after gluten challenge in children known not to suffer from coeliac disease.

with other small bowel enteropathies implies that this phenomenon is not specific to $\mathrm{CD}$. In the patients with intolerance of cow's milk protein, the highest count was seen in a child in whom a biopsy was performed during a cow's milk challenge. In the group with giardiasis there was no correlation between the count and the severity of the infestation as judged from the number of giardia lamblia seen on the biopsy specimen. The patients with 'intractable diarrhoea' with the highest counts were those whose duration of symptoms was longest.

The function of intraepithelial lymphocytes is not well understood. The importance of the gutassociated lymphoid tissue in the immune response is well recognized (Dolezel and Bienenstock, 1971; Bienenstock, 1975), but most of the evidence supporting lymphocyte homing to the bowel relates to the lamina propria and Peyer's patches. GuyGrand et al. (1974), and Ferguson and Parrott (1972) have shown that intraepithelial lymphocytes do not behave in the same way as lamina propria lymphocytes and neither was able to demonstrate that they were antigen driven. Marsh (1975a) in a study of mouse jejunum has shown that many epithelial lymphocytes show ultrastructural features of activation and potential for blast cell transformation. It is notable that the lymphocytes are located basally within the epithelium and Marsh (1975b) has further demonstrated migration of these cells across the epithelial basement membrane, at all points, into the lamina propria. The current finding of raised counts in children with various enteropathies, in some of which antigen-antibody reactions and complement activation are known to occur, supports the hypothesis that lymphocytic migration in the jejunal epithelium may well occur in response to the presence of specific antigen in the bowel lumen.

We are indebted to $\operatorname{Dr}$ A. H. Cameron for the histological preparation of the jejunal mucosa biopsy specimens, and to Dr C. J. Rolles for the clinical care of those patients who received a gluten challenge.

\section{References}

Bienenstock, J. (1975). The local immune response. American Journal of Veterinary Research, 36, 488-491.

Dissanayake, A. S., Truelove, S. C., and Whitehead, R. (1974). Jejunal mucosal recovery in coeliac disease in relation to the degree of adherence to a gluten-free diet. Quarterly Journal of Medicine, 43, 161-185.

Dolezel, J., and Bienenstock, J. (1971). Gamma A and non-gamma $\mathbf{A}$ immune response after oral and parenteral immunization of the hamster. Cellular Immunology, 2, 458-468.

Ferguson, A., and Murray, D. (1971). Quantitation of intraepithelial lymphocytes in human jejunum. Gut, 12, 988-994.

Ferguson, A., and Parrott, D. M. V. (1972). The effect of antigen deprivation on thymus-dependent and thymusindependent lymphocytes in the small intestine of the mouse. Clinical and Experimental Immunology, 12, 477-488.

Fry, L., Seah, P. P., McMinn, R. M. H., and Hoffbrand, A. V. (1972). Lymphocytic infiltration of epithelium in diagnosis of gluten-sensitive enteropathy. British Medical Journal, 3, 371-374.

Guy-Grand, D., Griscelli, C., and Vassalli, P. (1974). The gut-associated lymphoid system: nature and properties of the large dividing cells. European Journal of Immunology, 4, 435-443.

Holmes, G. K. T., Asquith, P., Stokes, P. L., and Cooke, W. T. (1974). Cellular infiltrate of jejunal biopsies in adult coeliac disease in relation to gluten withdrawal. Gut, 15 , 278-283.

Hourihane, D. O' B. (1966). The pathology of malabsorption states. In Recent Advances in Pathology, 8th edn, pp. 320347. Edited by C. V. Harrison. Churchill: London.

Kumar, P. J., Silk, D. B. A., Marks, R., Clark, M. L., and Dawson, A. M. (1973). Treatment of dermatitis herpetiformis with corticosteroids and a gluten-free diet: a study of jejunal morphology and function. Gut, 14, 280-283.

Marsh, M. N. (1975a). Studies of intestinal lymphoid tissue. I. Electron microscopic evidence of 'blast transformation' in epithelial lymphocytes of mouse small intestinal mucosa. Gut, 16, 665-674.

Marsh, M. N. (1975b). Studies of intestinal lymphoid tissue. II. Aspects of proliferation and migration of epithelial lymphocytes in the small intestine of mice. Gut, 16, 674-682. 